\title{
A THEORETICAL PERSPECTIVE OF DESIGNING FOR SAFE URBAN PUBLIC PLACE: LEARNINGS FROM THE SOCIAL AND URBAN THEORISTS
}

\author{
Parama Mitra \\ Department of Architecture, School of Planning \& Architecture, Bhopal, India \\ Dr Suchandra Bardhan \\ Department of Architecture, Jadavpur University, Kolkata, India
}

\begin{abstract}
Since the history of evolution of cities, civilizations have developed means to make their settlements advanced in terms of efficiency, comfort and to foster safety. Thus, safety within cities, is an important factor that forms an integral part of city design. This "safety" is not related to engineered design only but connected to human behavior that forms a very important attribute in livable environments. The paper is based on a robust literature review that aim to investigate into the field of Urban Safety. It deals with several theories that are inter-connected and relate to this concept. The concept of safety in urban context is a very complicated construct and involves a large number of variables, thus is order to fine -tune this concept, a systematic scanning of several related fields of theories are undertaken. They are classified, categorized and further filtered into segments from which a large number of study parameters are identified that can contribute to the factor of urban safety in public areas. These parameters further could be used in further research to generate safety audit tool.
\end{abstract}

Keywords: public spaces, theoretical constructs, urban safety

Cite this Article: Parama Mitra, Dr Suchandra Bardhan, A Theoretical Perspective of Designing for Safe Urban Public Place: Learnings from the Social and Urban Theorists, International Journal of Advanced Research in Engineering and Technology, 10 (2), 2019, pp 381-388.

http://iaeme.com/Home/issue/IJARET?Volume $=10 \&$ Issue $=2$

\section{INTRODUCTION}

\subsection{Conceptual Constructs}

For conceptual understanding, the key-terminologies used in the title of this research have been studied and a working definition was derived. Thereafter, detail literature study has been done to conceptualize the research idea. 


\subsection{Concept of Safety}

In this study "safety "was the primary term. Here, by term "safety" is in an urban context, thus the basic definitions as enlisted by Directorate-General Justice, Freedom and Security, is the following:

"Research and experience in the field has shown that, when citizens ask for increased safety, they are referring not only to criminal behaviour, but to a number of factors that make the urban environment unsafe; these range from the real risk, to fear and uneasiness."

The Directorate has compiled an extensive discussion on the nature of "fear" and thus the consequent "feeling of safety". As per the document, "Urban safety" can depend on the following:

"1. The real risk of becoming the victim of intimidation, aggression or other acts of violence (whether it is with intent to rob or gratuitous violence);

2. Anti-social behaviour due to the breaking of the traditional codes of civil conduct (spitting, urinating in public, aggressive begging etc);

3. The lack of up-keeping of the area: maintenance of parks and public spaces, cleanliness, presence of police on the streets, doormen, repair of street furniture;

4. The feeling of not being safe, as opposed to the real danger, which is often connected to factors such as squalor, lack of easy routes, lack of vitality, poor street lighting etc.;

5. Fear and all factors along with it: fear considered as a subjective feeling, not necessarily linked to risk, but related to wider factors often far away from the specific site which one is afraid of."

Thus, the word "safety" coined in this research is a combination of the above-mentioned phenomenon, that the user of the space experiences due to the complex combination of diverse elements and situations.

\subsection{Concept of Public Place}

The term "public space" is a very common term but with multiple dimensions of understanding. Public space, can easily translate to - a place for public. This essentially identifies a property of an open-area accessible and usable by common mass. A public place includes both built and un-built areas. Going through historical definitions, as Elizabeth Blackmar (2006) has described it thus:

"In urban planning, public space has historically been described as "open space", meaning the streets, parks and recreation areas, plazas and other publicly owned and managed outdoor spaces, as opposed to the private domain of housing and work. However, the recent evolutions of the forms of urban settlement and the growing number and variety of semi-public spaces managed by private-public or entirely private partnerships questions this notion inherited from a legal perspective. Somehow today, public space needs to be understood as different from the public domain of the state and its subdivisions, but rather as a space accessible to the public. In terms of law, it is perhaps closer to the older concept of the "commons", although we have to recognize that today, at least in the western world, every bit of land is now regulated by the laws of property making it difficult to consider anything as common without encountering an entitled owner and manager"

In this research however, the historical definition stands true, as public space here is the "open space" that allows human interaction.

Looking through the pages of history a Greek Agora or Roman Forum are perhaps the earliest examples of designed public spaces and the with the Classical revival during Renaissance the Plaza and city squares emerged, that eventually evolved and our modern day 
A Theoretical Perspective of Designing for Safe Urban Public Place: Learnings from the Social and Urban Theorists

public places, social places are born. However, the archaeological excavations have discovered cities where "paths" or "roads" have been the earliest "public places" as they enabled earliest human transfer, movement, transaction, communication and interaction.

In the current research, the term "public place" is used to understand, roads, specifically those within the city limits and act as indispensable mode of physical communication for the residents.

\section{LITERATURE REVIEW ON "SAFER PUBLIC SPACE"}

The research revolves around "Safer Public space", thus a wide range of literature needed to be examined, which had been classified into four broad categories.

a) Theories on Criminology, b) Theories on Human Cognition \& Behaviour, c) Theories of Public space design and d) Theories on Safer environment. These are explained subsequently in the following sections of the paper.

\section{Theories on Criminology}

Since the comprehension of "urban safety" requires a great deal of conceptual understanding of the concept of crime, criminal and motive, a stream of study was done to understand the theories. The theories which come under geographic profiling are identified as they relate with the requirement of this study.

3.1. Geographic profiling identifies crime in spatial context; it is an investigative approach to assess locations connected to the probable areas for location of offenders.

3.2. "Routine Activity Theory" by Cohen and Felson (1979), the absence of surveillance and identification of conflict points are discussed as the prime factors of concern according to this theory. "The theory stipulates three necessary conditions for most crime; a likely offender, a suitable target, and the absence of a capable guardian, coming together in time and space. In other words: for a crime to occur, a likely offender must find a suitable target with capable guardians absent."

3.3. "Environmental Criminology" by Patricia and Paul Brantingham (1980), focuses on criminal patterns within particular built environments and analyzes the impacts of these external variables on people's cognitive behaviour. This theory majorly discusses about crime mapping and identifying crime hot-spots.

3.4. "Behavioural Geography and Crime Pattern theory" initially developed by Brantingham and Brantingham (1981) and thereafter by Rengert and Wasilchick(1985), explained concepts like Crime generators, attractors and enablers; relation of long-distance travel to attractors of crime, use of mental maps in the study process.

3.5. "Situational Crime Prevention" by Clarke and Homel (1997) discusses 16 opportunity reducing techniques increasing perceived effort, increasing perceived risk, reducing anticipated rewards, removing excuses.

\section{THEORIES ON HUMAN COGNITION AND BEHAVIOUR}

The stream of theories on Human cognition and behavior were studied as the research is targeted on people and their spatial behavior, needs and response pattern. This triggered a detailed study of the behavioural patterns that people demonstrate in public areas. This particular study was aimed to understand the perceptional attributes that comprise very important parameters of study. The theories that mainly referred in the process are as follows.

4.1. The Gestalt Theory, the concept of "whole" or "from". Although the concept got global introduction from the Berlin school, the Austrian philosopher Ehfrenzel's greatest contribution was on Gestalt qualities that discussed the perception "at a glance" or "immediate perception". 
Later Kurt Koffka and Kohler further worked on this theory and investigated the domain of human perception. Several principles or laws related in this field was identified like "Law of proximity", "Law of continuity", "Law of common fate", "Law of closure" etc; that help people to understand their immediate surroundings.

4.2. The Theory of Hierarchy of needs by Abraham Maslow is a representational diagram showing how human beings strive to achieve starting from the lowest tire of needs. It is imperative to say that before human strives of higher pursuits they have to defend their basic need which form the lowest tier, ie; "food-clothing-shelter". Thereby human- need gradually rises up till the highest need, of "self-actualization" is achieved.. In this model, the $2^{\text {nd }}$ tier from base is that of "safety". Thus the theory ascertains the importance of the factor, "feeling of safety" as a $2^{\text {nd }}$ basic pre-requisite for ascertaining general human living condition. The lower levels are known as "deficiency needs", which has to be fulfilled for survival before graduating to the higher levels which are known as "growth or being needs". The study is focused on "safety" as a crucial human need and this theory supports that substantially

4.3. The Theory of Proxemics by E T Hall, an American anthropologist, is a study based on "distances" considering culture of a place and "social cohesion" This theory discusses the importance of inter-personal space and its connection to human comfort. His theory talks about physical distance that human beings prefer based on the relationship, situation and culture. This theory explains the concept of discomfort that can be generated due to inappropriate spacing. In the book 'Hidden Dimension", this concept is detailed and forms a strong parameter to judge human perception achieved through non-verbal communication.

4.4. Environment Behaviour Studies by Amos Rapoport. "His main aim was to define the importance of culture in the built environment and architecture; this is especially highlighted in his 1969 book 'House Form and Culture"'. According to his work, behavior of people is linked to "cognition" which is linked to elements of design. This theory emphasizes the concepts of "hierarchy of spaces", "privacy", "role of women" which also helped in the construction of perceptible or observable parameters.

4.5. Theory of Personal Space by Robert Sommer. Working on the lines of the Theory of Proxemics, Sommer coined the term "personal space" which is the immediate space surrounding people where people feel threatened or comfortable. This theory helps in determining non-verbal space- preference universal in human beings. The observational parameters could be determined form the study of this theory.

4.5. Privacy Regulation Theory by Irwin Altman, discusses the cultural aspects of privacy. He studied the behavioural aspects of men based on verbal, non-verbal, environmental and cultural parameters and established how these factors modify the "privacy mechanisms" thus affecting the social relationship. These aspects were found to be related to the current research as it linked with human " psychological -comfort" that can be associated with human feeling of safety.

\section{THEORIES OF PUBLIC SPACE DESIGN}

There are extensive researches and studies done by urban designer and planners on Public space design. These theories were scanned to identify the parameters which are suitable for the current research. Since the thesis is concerned about the safety of people in public space, specifically Indian urban streets, it was imperative to study these texts and understand the important design parameters. Those that were mostly identified to be linked to this research is as follows.

5.1. Imageability of Cities by Kevin Lynch. In his book, Image of the Cities, Lynch discussed the parameters which actually made cities "legible" or identifiable and memorable. He coined term "Imageability" as the ability of a city to be remembered by people. The 5 elements of 
A Theoretical Perspective of Designing for Safe Urban Public Place: Learnings from the Social and Urban Theorists

"imageability", path, district, edge, node and landmark, the image-able elements also fit into the set of observable parameters in the current research. (Kevin Lynch - The Image of City)

5.2. Pattern Language. This book by Christopher Alexander discusses in depth about the pattern of our built world and its link to the user behavior. Some of the parameters he discussed has been found to be useful in the current research.

5.3. The Social Life of Small Urban Spaces by William Whyte is a literature source that describes in detail the processes followed in designing socially active urban spaces. This provided with a large number of measurable parameters that could be used in the survey.

5.4. Quality of Physical Environment by Jan Gehl is focused on the study of improving the quality of public urban areas. In this literature, it was established the "opportunity" increase can create more "comfort, delight and protection", which in turn will cause a highly functional place. It was also established that rather than necessary activities, it is the alternative choices or options that resulted in lively public places.

5.5. Good city Form by Kevin Lynch in his seminal work that discusses how the "goodness" of the city can be identified. His work revolves around the city-size, its growth and conservation and finally culminates into conceptual basis of good urban design. The performance dimension of the city and meta- criteria are identified here which has been used as an important parameter of study during the safety survey.

\section{THEORIES ON SAFER ENVIRONMENT.}

The following literature works form the core study in the current research domain. The major works referred for the purpose are as follows.

6.1. The concept of "Eyes on Street". The revolutionary work by Jane Jacob, the writer and activist, "Death and Life in Great American cities" is considered as a path-breaking literature in the field of "safer city". This book enabled not only to formulate the basic understanding, consolidate the concept of public life, urban area and safety condition, but also helped in problem identification in a bigger domain. This literature helped to formulate the pattern of study, create a sensitivity towards the issue and identify many other literatures and works that continued in this direction.

6.2. Social aspects of Housing in Urban design by Elizabeth Wood in her book "Housing Design: A social Theory" (1961) is a novel work which for the first time in urban literature investigated into the gaps between the developers and users in a housing community and seeked to bridge it. In her work, she advocated a rich diversity in user group, in race, education and profession for a vibrant community. This work, identified several other parameters like, the ratio of road width to building height for more interaction, scale and visibility.

6.3. Crime Prevention Through Environmental Design or CPTED, as its acronym is popularly known to all Urban planners and urban designers, is a robust research work done by many people through a long period of time. Originally coined by Geoffery Ray, a criminologist about 1971. Later the same term was used by Oscar Newman in his research work, published as a book "Defensible Spaces" in 1972. A new model for CPTED was developed by T Crowe in 1990s where the approach was established as "multidisciplinary" one, wherein it was advocated that "any model of crime prevention must include both brain and physical environment".

6.4. Defensible Space by Oscar Newman (1971) is a literary work based on the research conducted by the architect himself to investigate the reasons for crime, vandalism and social isolation in housing complexes. In this research, the author validated a set of definitive parameters that are linked with crime and thus rendering a place "unsafe". This literature has 
been of profound importance on selection of parameters for safer environment study. The parameters thus adopted for the current research are, Hierarchy of open space, Natural surveillance, territoriality, Image and Mileu.

6.5. Prospect-refuge theory by Jay Appleton (1975) is a literary work that discusses criminology with reference to physical parameters. This seminal work on prospect-refuge theory is The Experience of Landscape by Jay Appleton, John Wiley \& Sons, 1975. This theory suggests that "people prefer edges rather than middle spaces, spaces with ceilings or covers overhead; spaces with few access points (protected at the back or side); spaces that provide unobstructed views from multiple vantage points; and spaces that provide a sense of safety and concealment. The preference for these elements is heightened if the environment is perceived to be hazardous or potentially hazardous." (http://people.sunyit.edu/ lepres/thesis/principles/193)

6.6. Vulnerability factors associated with neighbourhoods was discussed by Barbara Brown and Irwin Altman in their work published in 1983 in the Journal of Environmental Psychology as "Territoriality, defensible space and residential burglary: An environmental analysis". It is explains the concept of "Social climate" and "direct and symbolic barriers" and various other factors that enables walkable community design.

6.7. Broken Window Theory, an academic theory proposed by James Q. Wilson and George Kelling in 1982, stated the importance of maintenance and presence or absence of disorder in occurrence of crime within a community. This theory used the term "broken window" as a metaphor to describe, disturbance, incivility in an area that can be identified with illmaintenance and signs of damage or disorder. These factors were found to be suitable as parameter in the current research.

6.8. Typology of perception of safety by Fisher and Nasar in 1992, explains the quality of space and the perception of people based on enclosure and access points in the public area. The following chart explains the concept. From the study, the parameters of entry, exit, openness and enclosure are derived that are used in the current research.

\section{CONCLUSION: SUMMARY OF THE LITERATURE REVIEW}

This extensive study helped in understanding the existing theories that are related to design and perception that are used to identify the safety condition of a place. From this, a large number of parameters can be identified for the purpose of designing a safety audit tool that will investigate into the degree of safety of an urban area. Table 1.1 gives an overview of the parameters.

Table 1 Parameters related to Urban safety in public spaces

\begin{tabular}{|c|c|c|c|c|}
\hline Sl.No. & Source Theory & measurable & observational & perceptional \\
\hline \multirow{6}{*}{1} & \multirow{6}{*}{$\begin{array}{l}\text { Theories on } \\
\text { criminology }\end{array}$} & active surveillance & surveillance & target hardening \\
\hline & & & conflict points & access control \\
\hline & & & $\begin{array}{l}\text { location/ outdoor built } \\
\text { environment }\end{array}$ & $\begin{array}{l}\text { Entry/exit } \\
\text { screening }\end{array}$ \\
\hline & & & edge/ boundaries & target removal \\
\hline & & & $\begin{array}{l}\text { opportunity reducing } \\
\text { elements }\end{array}$ & $\begin{array}{l}\text { identifying } \\
\text { property }\end{array}$ \\
\hline & & & passive surveillance & $\begin{array}{l}\text { facilitating } \\
\text { compliance }\end{array}$ \\
\hline \multirow[b]{2}{*}{2} & \multirow[b]{2}{*}{$\begin{array}{l}\text { Theories on } \\
\text { human cognition } \\
\text { and behaviour }\end{array}$} & \multirow{2}{*}{$\begin{array}{l}\text { distance preference- } \\
\text { intimate, personal, } \\
\text { social and public } \\
\text { distances }\end{array}$} & territoriality & sense of ownership \\
\hline & & & $\begin{array}{l}\text { Law of proximity, } \\
\text { continuity, common }\end{array}$ & $\begin{array}{l}\text { privacy, crowding, } \\
\text { isolation, } \\
\text { territoriality }\end{array}$ \\
\hline
\end{tabular}


A Theoretical Perspective of Designing for Safe Urban Public Place: Learnings from the Social and Urban Theorists

\begin{tabular}{|c|c|c|c|c|}
\hline & & & $\begin{array}{l}\text { fate, closure, } \\
\text { symmetry, pragnanz }\end{array}$ & \\
\hline \multirow{9}{*}{3} & \multirow{9}{*}{$\begin{array}{l}\text { Theories on Safer } \\
\text { Environment }\end{array}$} & $\begin{array}{l}\text { width of sidewalks, } \\
\text { lighting distances, } \\
\text { visual access, edges }\end{array}$ & territoriality & $\begin{array}{l}\text { image, mileu, safer } \\
\text { adjascent spaces }\end{array}$ \\
\hline & & $\begin{array}{l}\text { visibility, enclosure, } \\
\text { aspect ratio }\end{array}$ & diverse activity & $\begin{array}{l}\text { clear demarcation } \\
\text { between public } \\
\text { and private spaces, }\end{array}$ \\
\hline & & scale & $\begin{array}{l}\text { material of street } \\
\text { furniture, landscape }\end{array}$ & $\begin{array}{l}\text { purpose of use of } \\
\text { the space }\end{array}$ \\
\hline & & $\begin{array}{l}\text { openness, enclosure, } \\
\text { entry/exit }\end{array}$ & $\begin{array}{l}\text { territorial markers, } \\
\text { adjacent activity } \\
\text { spaces }\end{array}$ & image \\
\hline & & $\begin{array}{l}\text { enclosure, access } \\
\text { points }\end{array}$ & $\begin{array}{l}\text { access control, entry } \\
\text { exit screening, } \\
\text { surveillance }\end{array}$ & visibility \\
\hline & & & physical barriers & symbolic barriers \\
\hline & & & $\begin{array}{l}\text { signs of ill } \\
\text { maintenance }\end{array}$ & sign of disorder \\
\hline & & & $\begin{array}{l}\text { doors, porches, shrubs, } \\
\text { gates, bollards } \\
\text { (physical design } \\
\text { elements), location of } \\
\text { windows, unobstructed } \\
\text { views, sidewalks, } \\
\text { landscaping }\end{array}$ & adequate lighting, \\
\hline & & & & $\begin{array}{l}\text { residents } \\
\text { participation }\end{array}$ \\
\hline \multirow{8}{*}{4} & \multirow{8}{*}{$\begin{array}{l}\text { Theories on } \\
\text { Design of Public } \\
\text { places }\end{array}$} & \multirow[b]{2}{*}{$\begin{array}{l}\text { amount of sitting: - } 1 \\
\text { liner foot of sitting for } \\
\text { every } 30 \text { sqft of plaza. }\end{array}$} & $\begin{array}{l}\text { path, nodes, district, } \\
\text { landmark, edge }\end{array}$ & $\begin{array}{l}\text { ambiguity,void, } \\
\text { simplicity, not } \\
\text { connectedness }\end{array}$ \\
\hline & & & $\begin{array}{l}\text { scale, boundaries, } \\
\text { alternating repitition, } \\
\text { goodness in shape, } \\
\text { positive space, local } \\
\text { symmetry, contrast }\end{array}$ & uses of the place \\
\hline & & $\begin{array}{l}1 \text { tree/ } 25 \text { feet } \\
\text { sidewalk of } 35^{\prime \prime} \text { dia }\end{array}$ & & $\begin{array}{l}\text { activity types- } \\
\text { necessary, } \\
\text { optional, resultant }\end{array}$ \\
\hline & & $\begin{array}{l}1,200 \text { watts/ } 4000 \mathrm{sqft} \\
\text { or a fraction thereof }\end{array}$ & & Vitality \\
\hline & & $\begin{array}{l}\text { width } 36 " \text {, slope } 1 \text { in } \\
12\end{array}$ & & sense \\
\hline & & & & Fit \\
\hline & & & & Access \\
\hline & & & & Control \\
\hline
\end{tabular}

\section{REFERENCES}

[1] Alexander, C.A. A Pattern Language: Towns Buildings Constructions. Oxford University Press, NY. (1977).

[2] Altman, Irwin. The Environment and Social Behavior: Privacy, Personal Space, Territory, Crowding. Reprint. Irving Publishers, 1975 
[3] A. Cartenì, M. L. De Guglielmo, N. Pascale, M. Calabrese, An Adaptive Rational DecisionMaking Process for Developing Sustainable Urban Mobility Plans, International Journal of Civil Engineering and Technology (IJCIET), Volume 8, Issue 7, July 2017, pp.1147-1156.

[4] Appleton, Jay. The Experience of Landscape. Revised Edition. University of Michigan. WileyBlackwell. (1996).

[5] Blackmar, Elizabeth. "Appropriating "the commons": the tragedy of property right discourse.", edited by Setha Low and Neil Smith. New York: Routledge 2006.

[6] Brantingham, P.J and Brantingham, P.L Patterns in Crime. New York:MacMillan.(1984).

[7] Brantingham, P.L. and P.J. Bran tingham Notes of the geometry of crime, in P.J. (1981b)

[8] Clarke, R.V. Situational Crime Prevention: Successful Case Studies, Second Edition, Monsey, NY: Criminal Justice Press. (1997)

[9] Ar. Chinna Saidulu, Architectural and Urban Design Interventions to Mitigate Impacts of Urban Heat Islands on Urban Dwellers. International Journal of Architecture (IJA), 3(1), 2017, pp. 3642.

[10] Crowe,T. Crime Prevention through Environmental Design. Edition 2. National Crime Prevention Institute. Butter worth-Heinemann publications, Woburn, MA. (1999)

[11] Felson, M. and L.E. Cohen. Human ecology and crime: A routine activity approach. Human Ecology. (1980).

[12] Gehl, Jan. Cities for People. 1st Edition. Island Press, Washington. (2010).

[13] Hall, E.T. Hidden Dimension, Reprint 1990, Anchor Books Edition, NY: Doubleday, Random House, Inc. (1966)

[14] B. Rajasekhar and Dr. G. Venkata Ramana and Dr. G. K. Viswanadh, Assessment of NonRevenue-Water and its reduction measures in Urban Water Distribution systems, International Journal of Civil Engineering and Technology, 9(6), 2018, pp. 1079-1087

[15] HANDBOOK on Crime Prevention Guidelines for urban planning and design, European Commission - Directorate-General Justice, Freedom and Security (Contract JLS/2006/AGIS/208)

[16] Jacobs, J. The Death and Life of Great American Cities. New York: Random House (1961).

[17] Lynch,Kevin. Image of The City. Reprint.Cambridge, MIT Press. (1960).

[18] Newman, O. Defensible Space: Crime Prevention Through Urban Design. New York: MacMillan (1972).

[19] Rapoport, Amos. House Form and Culture. PRENTICE-HALL, INC., Englewood Cliffs, N.J. (1969). https://openlibrary.org

[20] Renegart, G.F., and Wasilchick, J. Suburban burglary: A time and place for everything. Springfield, IL:Charles C.Thomas. (1985).

[21] Whyte,W.H. The social life of small urban spaces. Edition 8. Project For Public Spaces Inc. (1981).

[22] Wilson, J.Q.,and Kelling, G.L 'Broken Windows: The Police and Neighborhood Safety'. The Atlantic Monthly (March) (1982). 